\title{
O CONCEITO DE CONSUMIDOR E FORNECEDOR BANCÁRIOS
}

\section{Rodrigo Brum Silva}

SUMÁRIO: 1. Introdução. 2. A Concepção Constitucional do Consumidor. 3. O Nascimento do Código. 4. Resenha Histórica do Desenvolvimento dos Bancos. 5. A Relação de Consumo. 5.1. A Extensão do Conceito de Consumidor. 5.2. O Consumidor Bancário. 5.3. A Extensão do Conceito de Fornecedor. 5.4. O Fornecedor Bancário. 6. Conclusão. 7. Bibliografia.

SUMMARY: 1. Introduction. 2. The Consumer's Constitutional Conception. 3. The Origin of the Code. 4. Historical Development of the Banks. 5. Consumption Relationship. 5.1 The Extension of the Consumer Concept. 5.2 The Bank Consumer. 5.3 The Extension of the Vendor Concept. 5.4 The Bank Vendor. 6. Conclusion. 7. Bibliography.

SUMARIO: 1. Introducción. 2. La Concepción Constitucional del Consumidor. 3. El Origen del Código. 4. El Desarrollo histórico de los Bancos. 5. La Relación del consumo. 5.1 La Extensión del Concepto de Consumo. 5.2 El Consumidor Bancario. 5.3 La Extensión del Concepto de Vendedor. 5.4 El Vendedor Bancario. 6. Conclusión. 7. Bibliografia

RESUMO: O presente artigo trata dos conceitos de consumidor e de fornecedor, insertos no Código de Defesa do Consumidor, através de uma interpretação extensiva,

Mestrando en Direto Negocial pela Universidade Estadual de Londrina. Advogado em Londring $P R$. 
coerente com os objetivos constitucionais, de modo a demonstrar que as casas bancárias e instituições financeiras são fornecedoras de produtos e de serviços à sua clientela, havendo plena aplicabilidade da Lei $n^{-a} 8078 / 90$ nesta forma de relação.

ABSTRACT: The present article is about consumer and vendor concept, inserted in the Code of Defense of the Consumer, through an extensive interpretation, coherent with the constitutional objectives, in way to demonstrate that the bank houses and financial institutions are vendors of products and services to their clientele, having full applicability of the Law no. 8078/90 in this relationship form.

RESUMEN: El artículo presente trata del concepto de consumidor y vendedor en el Código de la Defensa del Consumidor, por una interpretación extensa, coherente con los objetivos constitucionales, para demostrar que las casas y las instituciones financieras bancarias son vendedores de productos y servicios a su clientela, teniendo la aplicabilidad repleta de la Ley no. $8078 / 90$ en esta forma de la relación.

PALAVRAS-CHAVE: Constituição. Consumidor. Fornecedor. Cliente. Banco. Conceito. Interpretação.

KEY-WORDS: Constitution. Consumer. Vendor. Client. Bank. Concept. Interpretation.

PALABRAS-LLAVE: Constitución. El consumidor. El vendedor. El cliente. El banco. El concepto. Interpretación.

\section{Introdução}

A Constituição Federal do Brasil, superando dogmas liberais e 
positivistas, que não mais suportavam a regulamentação dos fatos sociais, realizou profundas modificações no cenário jurídico nacional, principalmente quanto às relações civis, dentre as quais a inserção da defesa do consumidor no capítulo dos direitos e deveres individuais e coletivos, e no título dos direitos e das garantias fundamentais, além de sua classificação como princípio geral da ordem econômica.

A preocupação constitucional era tão acentuada, pois trabalhava no sentido de promover a dignidade da pessoa e à superação das desigualdades sociais, que determinou, em uma de suas disposições finais transitórias, que fosse elaborado um Código de Defesa do Consumidor.

Em obediência à determinação, surge o Código de Defesa do Consumidor, Lei $n^{a} 8078 / 90$, norma de ordem pública e interesse social, cogente e indisponível, que conceituando consumidor e fornecedor, acaba tornando indispensável, como regra geral, a existência de um vínculo, de uma interligação, que efetive a união dos pólos subjetivos da relação.

Com a elaboração e nascimento do Código, e sua classificação relacional polarizadora, nascem também as primeiras iniciativas de reação, advindas das classes detentoras do poder econômico, no sentido de restringir e até de excluir a abrangência interpretativa dos conceitos de fornecedor e de consumidor, ao fito de não serem alcançadas pelo sistema protetivo e defensivo incorporado pela norma.

Liderando esse agressivo movimento de reação, clara está a participação dos bancos, das instituições financeiras e de crédito, eis que até o presente data, quando passados mais de 10 (dez) anos da vigência do Código, não só não se enxergam como fornecedoras, contrariamente ao que está expresso na norma, mas também se insurgem no enquadramento de várias ordens de pessoas como consumidoras.

Entretanto, a importância das instituições financeiras é indissociável da vida social e econômica do país, seja por sua atuação no setor produtivo, financiando a atividade comercial, industrial, pecuária e agrícola, seja na prestação de serviços, seja na vida ordinária do homem, certo de que todos, não importando a que título, alguma vez em suas vidas hão de se relacionar com uma casa bancária.

Dentro desse quadro geral, importantíssimo o estudo das principais personagens da relação de consumo, na busca de revelar o que pode ser entendido pelas expressões consumidor bancário e fornecedor bancário, 
em uma abordagem abrangente, não restritiva, quanto ao significados e à significância dos conceitos, em uma interpretação que se coadune, harmoniosamente, com os objetivos e princípios propugnados pela norma constitucional, em busca de uma justiça social.

É exatamente isto que o presente trabalho propõe, sem qualquer pretensão de esgotamento do tema, face à brevidade indispensável a estudos desta natureza, passando pela origem constitucional, o nascimento do Código, o desenvolvimento histórico dos bancos, a relação de consumo e a caracterização de seus protagonistas, o consumidor e o fornecedor bancários.

\section{A Concepção Constitucional do Consumidor}

A Constituição Federal de 1988, positivando princípios fundamentais da República, sobretudo no que tange à promoção da dignidade da pessoa humana e à superação das desigualdades sociais e regionais, realizou a inserção da defesa do consumidor na categoria dos direitos e deveres individuais e coletivos, no título dos direitos e das garantias fundamentais ${ }^{1}$.

Comentando a inovadora inserção, desconhecida de nossas constituições anteriores, James Marins sustenta que "a inclusão desta matéria no plano constitucional, conforme afirma Reich, coaduna-se com a função do Estado em intervir em situações de desigualdade e desequilibrio social que não poderiam ser satisfatoriamente acomodadas ou corrigidas com o uso de instrumentos meramente políticos ou econômicos."2.

A inclusão constitucional da matéria se justifica, em face das patentes mudanças sociais e econômicas havidas no século XX, que clamavam, e ainda clamam, em plena transmodernidade 3 , por uma premente transformação jurídica, com a superação de dogmas liberais e positivistas, que não mais conseguem dar conta da regulamentação dos fenômenos sociais.

A inserção é o resultado identificável, também, do surgimento de uma nova ideologia, que ambiciona uma maior participação do Estado ${ }^{4}$ nas relações sociais privadas, certo de que este não pode assistir, como neutro

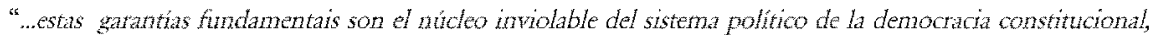
regiendo cono principios superiores al ordem juidico positivo, aun cuando no estén formulados em normas constitucionales expressas. Ern su totalidad, estas libertades findaneztales encarnan la diguidad del hombre."(LOWENSTEIN, K. Teoria de la Constifución. Barcelona: Ariel, 1970, $2^{\circ}$ ed., p. 390)

${ }^{2}$ Responsabilidade da Empresa pelo Fato do Produto. São Paulo: RT, 1993, p. 26.

"COELHO, L. F. Saudade do Futuro. Florianópolis: Boiteux, 2001, p. 41.

4Quanto à publiczação do Dícito Prvado e temas correlatos, é inovadora a abordagem, já em 1961, do Professor Michele Giorginni (O Direito Privado e suas Atuais Fronteiras. Porto Alegre RT, 1998, v. 787, p. 35-55).
} 
espectador de outrora, a existência de uma inverídica e superada igualdade formal (que em verdade mais desiguala), a serviço dos grupos que detêm o poder econômico.

Assim, quando o art. 5a , inc. XXXII, expressamente determina que a defesa do consumidor deverá ser desenvolvida pelo Estado, está fazendo uma verdadeira promoção social do consumidor, ou seja, do grupo dos juridicamente excluídos, dos economicamente arrasados e dos moralmente humilhados, enfim, de todo aquele que tem de se submeter à sanha capitalista dos fornecedores.

Da mesma forma, quando a Constituição, no art. 170, inc. V, eleva a defesa do consumidor ao status de princípio essencial da ordem econômica, no mesmo plano dos princípios da soberania, da função social da propriedade, da livre concorrência, do meio ambiente ${ }^{5}$, entre outros, está a significar, no mínimo, que o Judiciário e o Legislativo não poderão privilegiar, por exemplo, a propriedade privada, ou a livre concorrência, em detrimento do consumidor, eis que estão em ordem de paridade principiológica ${ }^{6}$, que deverá ser sopesada e resolvida à luz da proporcionalidade?.

Com efeito, como revela Walter Ceneviva "...o conteúdo material da Carta Magna é interpretado sistematicamente, no seu conjunto, evitada a leitura de norma isolada que privilegie a livre empresa ou ponha toda força no termo defesa em relação ao destinatário final do consumo".

Não obstante isso, é necessário ressaltar que a concepção da defesa do consumidor no âmbito da Constituição Federal, seja como direito individual e coletivo, seja como princípio da ordem econômica, obriga uma interpretação infraconstitucional à sua luz, não somente em razão da sua hierarquia normativa, supremacia, imperatividade ou eficácia", mas em virtude do fundamento valorativo que acolhe, isto é, à realização da pessoa em todos os seus aspectos, assegurando a todos uma existência digna, conforme os ditames da justiça social.

${ }^{5}$ Com entendimento em contrário está Manoel Gonçalves Ferreira Filho, que enxerga na norma apenas a enfatização da proteção do consumidor contra abusos praticados pelos fornecedores (Curso de Direito Constitucional. São Paulo: Saraiva, 1990, $18^{\circ}$ ed., p. 303).

' COMPARATO, F. K. A Proteção do Consumidor na Constituição Brasileira. São Paulo: Revista de Direito Mercantil, v. 80, p. 70-71.

BARROS, S. T. O princípio da Proporcionalidade e o Controle de Constitucionalidade das Leis Restritivas de Direitos Fundamentais. Brasília: Brasília Jurídica, 1996, p. 153-179.

" Publicidade e Direito do Consumidor. São Paulo: RT, 1991, p. 81.

"A respeito da aplicação direta das normas constitucionais, é interessante o trabalho desenvolvido pela Professora Maria Celina B. M. Tepedino (A Caminho de um Direito Civil Constitucional. São Paulo: Revista de Direito Civil, Imobiliário, Agrário e Empresarial, 1993, nª 65, p. 433-438). 
Além dos dispositivos supra comentados, que constituem a verdadeira gênese da matéria consumerista na seara constitucional, a Constituição Federal, em outros momentos normativos, busca privilegiar a situação jurídica do consumidor, seja de forma direta, como demonstram os arts. $24^{\mathrm{a}}$ e $150, \S 5^{\mathrm{a}}$, que tratam, respectivamente, da competência legislativa e da informação tributária ao consumidor, seja de forma indireta, como no art. 175, parágrafo único, inc. II, quando utiliza a expressão 'os direitos dos usuários'.

Apenas para finalizar o tópico, é preciso ressaltar que a defesa do consumidor era um objetivo tão presente na elaboração e promulgação da Constituição Federal, que o art. 48, do Ato das Disposições Constitucionais Transitórias, visando a efetiva regulamentação da matéria, determina expressamente a elaboração de um Código de Defesa do Consumidor, no prazo de cento e vinte dias.

\section{O Nascimento do Código}

Em decorrência da diretiva constitucional, no dia 11.09.90, ainda que fora do prazo determinado, nasce o Código de Defesa do Consumidor, fruto do 'movimento consumerista brasileiro', que teve como padrinhos, pois autores do anteprojeto, brilhantes juristas pátrios, como Ada Pellegrini Grinover, Antônio Herman de Vasconcellos e Benjamin, Daniel Roberto Fink, José Geraldo Brito Filomeno, Kazuo Watanabe, Nelson Nery Júnior e Zelmo Denari ${ }^{10}$.

Sem que entremos a fundo na problemática da descodificação ${ }^{11}$ e da existência de um verdadeiro microssistema ${ }^{12}$, com o nascimento dessa lei especial, cabe constatar que o início da vigência do Código de Defesa do Consumidor, em março de 1991, marca um ponto histórico de afastamento da aplicação de grande parte do Código Civil e do Código Comercial, eis que matérias tradicionalmente por eles tratadas, como o negócio jurídico, tipicamente materializado no contrato, sofrem a abrangència e os efeitos das novas normas protetivas, mais hábeis à consolidação de uma igualdade substancial.

\footnotetext{
FILOMENO, J. G. B. at ali. Código de Defesa do Consumidor - Comentado pelos Autores do Anteprojeto. Rio de Janeiro; Forense Universitária, $1997,5^{2}$ ed., p. 22.

"GOMES, O. A Agonia do Código Civil. Rio de Janeiro: Revista de Direito Comparado LusoBrasileito, Forense, 1988, v. 757, p. 172-180.

12 KARAM, M. O Processo de Codificação do Direito Civil - Inovaçóes da Parte Geral e do Livro das Obrigaçóes. São Paulo: Revista dos Tribunais, 1998, w. 757, p. 11-28.
} 
Maior prova desse fato, está consignada no próprio art. $1^{\text {a }}$, que estabelecendo como de ordem pública e de interesse social, as normas do Código de Defesa do Consumidor, está a dizer que os dispositivos são cogentes, verdadeiramente inderrogáveis pela vontade dos particulares ${ }^{13}$, tudo em prol do efetivo equilíbrio entre as partes na relação material de consumo, fato que muito o afasta do sistema oitocentista, adotado pelo Código Civi1 ${ }^{14}$, que via na autonomia da vontade a maior expressão do dogma absoluto da liberdade do indivíduo.

Ressaltando a natureza de ordem pública e de interesse social das normas do Código de Defesa do Consumidor, José Geraldo Brito Filomeno afirma que "...embora se admita a livre disposição de alguns interesses de caráter patrimonial, ...", como é o caso do art. 107, que dispõe sobre as convençôes de consumo, "o caráter cogente, todavia, fica bem marcado sobretudo na Seção II do Capítulo IV ainda do Título I, quando se trata das chamadas "cláusulas abusivas', fulminadas de nulidade (cf. 51 do Código), ou então já antes, nos arts. 39 a 41 que versam sobre as práticas abusivas." ${ }^{.15}$.

Inobstante a indiscutível cogência, vale dizer que o objetivo do Código não é o de substituir a vontade das partes, dentro da relação de consumo, pura e simplesmente, pela vontade do Estado, mas sim o de realizar uma verdadeira igualdade, que não poderia acontecer sob o império do poder econômico e fático do fornecedor, em pleno detrimento do consumidor.

O que ocorre, por meio do Código de Defesa do Consumidor, é a verificação de um fato há muito conhecido pelo senso comum, ou seja, de que o poder econômico corrompe a relação entre os agentes de consumo, em beneficio do hipersuficiente, que tem à sua disposição os recursos materiais e imateriais necessários para dirigir a sua forma e o seu conteúdo ${ }^{16}$, além da sua criação, modificação e extinção.

Assim há, claramente, uma contraposição do poder jurídico com poder de fato, para a defesa e a proteção dos desfavorecidos, hipossuficientes, que não possuindo os recursos, a informação ou a solidez de vontade,

\footnotetext{
13 ALVTM, A. et alit. Código do Consumidor Comentado. Sảo Paulo: RT, 1991, p. 10.

a TEPEDINO, M .C. B. M. A Caminho de um Direito Civil Constitucional São Paulo: Revista de Direito Civil, Imobiliário, Agrário e Empresarial, 1993, aª 65, p. 433.

15 FILOMENO, J. G. B. et ali. Código de Defesa do Consumidor - Comentado pelos Autores do Anteprojeto. Rio de Janeiro: Forense Universitaria, $1997,5^{\mathrm{s}}$ ed., p. 23.

to "... No que se refere ao principio da igualdade. Ferreira de Almeida chama-o de ilusório, uma vez que os agentes econónicos se distinguem claramente entre si pelo seu poder econónico, o que gera diferentes graus de poder negocial. A igualdade formal, afirma, cria ou sustenta desigualdades de fato, e somente o tratamento juridico desigual, no sentido inverso da potencia económica, pode eliminalas." (COELHO, F. U. O Empresário e os Direitos do Consumidor. São Paulo: Saraiva, 1994, p. 40).
} 
indispensáveis para produzirem uma igualdade de fato, na acepção substancial, não formal, têm seus interesses devidamente protegidos, com o estabelecimento de direitos básicos que visam realizá-la.

Dentro desse contexto, importância ímpar ganha a temática da aplicação do Código de Defesa do Consumidor quanto ao relacionamento entre clientes e bancos, em nosso entendimento, tipicamente de consumo, fato que será devidamente analisado em item próprio, sendo necessário, antes, uma visão geral do desenvolvimento histórico das atividades realizadas pelos bancos e a sua influência na sociedade.

\section{Resenha Histórica do Desenvolvimento dos Bancos}

As práticas bancárias não eram desconhecidas na remota Antiguidade, constituindo um reflexo das atividades comerciais. Em Roma, comenta o historiador José Jobson de Arruda, uma das consequências das conquistas do mediterrâneo, com a vitória sobre Cartago, foi o surgimento de uma nova classe social, a dos cavaleiros, constituída de plebeus que possuíam algum capital e o investiram em atividades rendosas, "os lucros conseguidos nessas atividades aumentaram ainda mais o capital dos homens novos, que passaram a aplicá-lo em empréstimos a juros e na atividade bancária"1?

Entretanto, essa atividade, esporádica e peripatética, somente se estabelece quando se nota a dificuldade do dinheiro acompanhar os viajantes (com o inescusável risco de enormes fortunas caírem nas mãos de assaltantes), fato que obrigou os cambistas a organizar uma estrutura de comunicação e troca de débitos e honra de saques uns dos outros ${ }^{18}$.

Já na Idade Média, segundo Nelson Abräo, "com o florescimento do comércio, graças às feiras das cidades italianas, surgiram os campsores ou cambiatores, que praticavam a troca manual de moedas. Com o aperfeiçoamento de suas atividade, que evoluíram da simples troca de moedas para a creditícia propriamente dita, tornaram-se conhecidos por banqueiros, "nome esse que surgiu no século XII, e que depois se confundiu com os grandes mercadores e cujos nomes permaneceram na história" 19 .

\footnotetext{
17 Historia Antiga e Medieval. Säo Paulo: Ática, 1989, 119 ed., p. 41-103.

18 LUZ, A. D. da. Negócios Jurídicos Bancários. São Paulo: Juarez de Oliveira, $2^{\circ}$ ed. p. 7.

"Direito Bancário. São Paulo: RT, $1998,4^{\circ}$ ed., p. 32
} 
Na modernidade, com a Revolução Industrial, que operou a consolidação do capitalismo liberal, surgiram as condições ideais para que os bancos atingissem seu pleno desenvolvimento, marcado pelo aparecimento dos grandes banqueiros, e a extensão dos serviços dos bancos para o plano internacional ${ }^{20}$.

Com efeito, o historiador Antonio Pedro afirma que "ao mesmo tempo que isto acontecia na indústria, um processo análogo concentrava o capital bancário nas mãos de alguns grandes bancos. Com essa concentração, as atividades bancárias ganharam novas dimensões: a rede de filiais se alastrou por todo o pais, permitindo ao banco controlar o desenvolvimento industrial, incentivando certos ramos e asfixiando outros, concedendo ou cortando créditos, respectivamente."

Em virtude desse desenvolvimento crescente, e com seus fortes reflexos na vida social, originado no poder de criar dinheiro, com a emissão de papéis, o Estado se viu obrigado a intervir, na proteção de clientes e poupadores, com a criação dos bancos do Poder Público, embriões dos atuais Bancos Centrais, que têm por função atuar na regulação do mercado e na disciplina da atividade financeira ${ }^{22}$.

Atualmente no Brasil, como no resto dos países em desenvolvimento, além de um banco oficial, existe uma grande quantidade de empresas bancárias particulares, surgidas na segunda metade do século XIX, e que se multiplicaram, já no século XX, a partir da lei que disciplinou o Sistema Financeiro Nacional, de n- 4595/64, que criou o Banco Central do Brasil e o Conselho Monetário Nacional ${ }^{23}$.

Diante dessa visão, ainda que perfunctória, impossivel não concluir a relevância dos bancos na atividade econômica e social, certo de que nenhum aspecto da vida transmoderna está livre de sua ação, seja através de sua importância no setor produtivo, no financiamento da atividade comercial, industrial, pecuária e agrícola, seja na vida do homem comum, que através dele satisfaz as suas necessidades mais ordinárias.

\footnotetext{
2) iden, ibidem, p. 33.

2) História Moderna e Contemporânea. Sào Paulo: FTD, 1991, p. 261.

${ }^{2}$ LUZ, A. D da. Negócios Juridicos Bancários. Săo Palo: Juarez de Oliveira, $2^{8}{ }^{4}$, p. 8.

23 idem, ibidem, p. 8 .
} 


\section{A Relação de Consumo}

O Código de Defesa do Consumidor do Brasil, fugindo a definições subjetivas $^{24}$, no art. $2^{\mathrm{a}}$, caput, afirma que o consumidor é toda a pessoa física ou jurídica que adquire ou utiliza produtos ou serviços como destinatário final. Da mesma forma, no art. $3^{\mathrm{a}}$, procurando a conceituação mais abrangente possível, o Código de Defesa do Consumidor conceitua o fornecedor, aqui em síntese, como todo aquele que provisione o mercado consumidor de produtos e de serviços ${ }^{25}$, através de uma remuneração.

Diante das conceituações propugnadas pela norma, podemos concluir que para haver aplicação do Código de Defesa do Consumidor, é indispensável à existência de uma relação de consumo, ou seja, de um vínculo relacional ${ }^{26}$, no mais das vezes de natureza contratual ${ }^{27}$, que una os dois sujeitos, de um lado o consumidor e de outro o fornecedor ${ }^{28}$.

Desta forma, para se identificar uma relação de consumo ${ }^{29}$, mister o conhecimento anterior dos dois conceitos indispensáveis, o de consumidor e o de fornecedor, cuja inexistência, nos pólos antagônicos, transformará a suposta relação consumerista em civil ou comercial.

\subsection{A Extensão do Conceito de Consumidor}

Sobre a extensão e o raio de aplicação do conceito objetivo formulado pela norma ${ }^{30}$, iniciativa legislativa que louvamos, na medida em que não restrinja o seu campo de incidência, trabalhando com fattispecie aberta ${ }^{31}$, surgem duas correntes doutrinárias divergentes, a dos finalistas e a dos maximalistas, que embora antinômicas, não são mutuamente excludentes, certo de que buscam, cada uma a seu modo, a melhor proteção possível para o consumidor.

\footnotetext{
23. "A definiç̃o juridica de consumidor nôno está assentada nem mesmo naqueles páses que possuem legisłação especial para protegê-lo. Por outro lado, é dificil definir consumidor com base apenas no direito tradicional" (BENJAMIN, A. H. B. O conceito Jurídico de Consumidor. Săo Paulo: RT, 1988, n"628, p. 70) 2. ALVMM, A et ahi Código do Consumidor Comentado. Săo Paulo: RT, 1991, p. 10.

3 COELHO, F. U. O Empresário e os Direitos do Consumidor. São Paulo: Saratya, 1994, p. 43.

37 "Essa relaçäo especial é normalmente estabelecida por um contrato entre o consumidor e o fornecedor, embora outras pessoas fora deste negócio jurídico podem também ser protegidos pelas normas do Código de Defesa do Consunidor, caso sofram um dano em razão de alguma prática comercial daquele fornecedor no mercado." (TIMM, L. B. A Prestação de Serviços Bancários Via Internet (home banking) e a Proteção do Consumidor. São Paulo: RT, 2001, Revista do Consumidor $n^{\sharp 1} 38$, p. 82).

2. "A relaça de consumo compreende o vinculo contratual de fornecimento e aquisição de produtos e serviços." (CENEVTVA, W. Publicidade e Direito do Consumidor. São Paulo: RT, 1991, p. 81).

z: "São relacoóes de consumo apenas aquelas que enwolven betrs (ou produtos) entregtes a seu destinatario final. O mestno conceito serve para os serviços, também abrangidos nas relaçôes de consumo." (DASQUALOTTO, A. Conceitos Fundamentais no Código de Defesa do Consumidor. São Paulo: RT, 1991, na 666, p. 50).

"CORLHO, F. U. O Empresário e os Direitos do Consumidor. São Paulo: Sarava, 1994, p. 40.

${ }^{31}$ Nesse sentido, é indispensável ressaltar o trabalho de Judith Martins Costa sobre as clausulas gerais (O Direito Privado como um "sistema em construçăo", Revista de Informaçăo Legislativa, $\mathrm{n}^{2}$ 139, Brasilia, 1998, p. 05-22).
} 
Os finalistas, que podemos, sem medo errar, considerar como os pioneiros do consumerismo ${ }^{32}$, e os que possuem o maior número de juristas em suas fileiras, enxergando que o consumidor é parte vulnerável da relação de consumo, como afirma o art. 4ª , inc. I, da Lei $\mathrm{n}^{\mathrm{a}}$ 8078/90, propõem que o critério de discrimine, entre um consumidor e um não consumidor, seja o merecimento da tutela, que pode ser avaliado pela interpretação restritiva da expressão 'destinatário final'.

\section{Nas palavras de Cláudia Lima Marques,}

"Destinatário final é aquele destinatário fático e econômico do bem ou serviço, seja ele pessoa jurídica ou física. Logo, segundo esta interpretação teleológica não basta ser destinatário fático do produto, retirá-lo da cadeia de produção, ..., é necessário ser destinatário final econômico do bem, não adquiri-lo para a revenda, não adquiri-lo para o uso profissional, pois o bem seria novamente instrumento de produção cujo preço será incluído no preço final do profissional que o adquiriu. Neste caso não haveria a exigida 'destinação final' do produto ou do serviço" ${ }^{3}$.

Como é fácil perceber, a corrente finalista restringe à aplicação do Código de Defesa do Consumidor, enquadrando somente aquele que utiliza o bem ou o serviço para o uso próprio ou de sua família, e não para a produção de outros bens ou outros serviços, eis que visualiza, como elemento determinante, a hipossuficiência, entendida como vulnerabilidade estritamente econômica.

A partir desse ponto de vista inicial, de forte tendência restritivista, os finalistas, também intitulados teleológicos, evoluíram para uma posição mais amena $^{34}$, que aceita a possibilidade de interpretar o art. $2^{\mathrm{a}}$ de um ponto de vista que reconhece a vulnerabilidade, em certos casos, da pequena empresa, do profissional, das fundações e das associações, mas sem fim lucrativos ${ }^{35}$, para a plena aplicabilidade do Código de Defesa do Consumidor.

Em contraposição a essa corrente doutrinária, a corrente maximalista entende o Código de Defesa do Consumidor como um regulamento de todo o mercado de consumo brasileiro, e não apenas de normas que visam proteger o não profissional, economicamente mais vulnerável.

\footnotetext{
${ }^{32}$ MARQUES, C. M. Contratos no Código de Defesa do Consumidor. São Paulo: RT, 1995, 2oe. ed., vol. 1, p. 100. 33 idem, ibidem, p. 100.

${ }^{34}$ idem, ibiden, p. 101.

${ }_{35}$ FILOMENO, J. G. B. et alii. Código de Defesa do Consumidor - Comentado pelos Autores do Anteprojeto. Rio de Janeiro: Forense Universitária, 1997, 5o ed., p. 31.
} 
Cláudia Lima Marques, com sua peculiar competência e exatidão, afirma que por esse entendimento "o CDC seria um Código geral sobre o consumo, um Código sobre a sociedade de consumo, o qual institui normas e princípios para todos os agentes do mercado, os quais podem assumir os papéis ora de fornecedores ora de consumidores. A definição do art. $2^{\text {a }}$, deve ser interpretada mais extensamente possivel, segundo esta corrente, para que as normas do CDC possam ser aplicadas a um número cada vez maior de relações do mercado. Consideram que a definição do art. $2^{a}$, é puramente objetiva, não importando se a pessoa tem ou não fim lucrativo quando adquire um produto ou utiliza um serviço. Destinatário final seria o destinatário fático do produto, aquele que o retira do mercado e o utiliza, o consome, ..."36.

Diante dessas duas correntes, em nossa modesta opinião, a razão se encontra entre os maximalistas.

Em verdade, uma visão que restringe o campo de aplicação do Código de Defesa do Consumidor aos critérios apenas da vulnerabilidade e da destinação final econômica do bem ou do serviço, não nos parece a interpretação mais adequada para a efetiva proteção do consumidor, nem à luz da Constituição Federal, que não restringe, nem à luz da própría Lei 8078/90, que em pelo menos dois artigos, alarga o seu campo de aplicação, sobretudo quando equipara a consumidores as pessoas submetidas às práticas comerciais abusivas.

Ora, existem situações onde a vulnerabilidade, apesar de não econômica, ou jurídica (científica), é fática, como os próprio finalistas admitem ${ }^{37}$.

Nesse sentido, tomemos o caso do advogado que, necessitando de obras jurídica para seu enriquecimento cultural, adquire de uma livraria determinados livros, e, infelizmente, ao chegar em seu escritório, constate que existem varias páginas em branco nos mesmos.

$\mathrm{Na}$ hipótese formulada, caso adotássemos uma visão finalista, o Código de Defesa do Consumidor nâo poderia ser aplicado, eis que o advogado não pode ser considerado o destinatário final econômico dos livros (ou dos conhecimentos neles depositados), pois deles poderia auferir lucros, transportando-se o pólo da destinação, unicamente, para os próprios clientes da sua banca de advocacia, que se beneficiarão da cultura jurídica percebida por seu causídico, através da leitura e da reflexão.

3ARQUES, C. M. Contratos no Código de Defesa do Consumidor. São Paulo: RT, 1995, 22 ed., vol. 1, p. 100. "idem, ibidem, p. 106. 
Ainda, dentro do exemplo formulado, sequer um acadêmico de direito poderia ser considerado consumidor, pois enriquecendo sua cultura, poderia estar enriquecendo também o seu patrimônio material, uma vez que o conhecimento adquirido poderia ser utilizado para favorecer a sua entrada, na qualidade de estagiário de direito, em um escritório de advocacia, cuja atuação proporciona à percepção de capital.

Da mesma forma, o profissional, pessoa física ou jurídica (pequena, média ou grande), jamais poderia reclamar a tutela consumerista quando é prejudicada por uma fornecedora que, por exemplo, na prestação de serviços de limpeza, executou incorretamente um serviço, certo de que o asseio e a limpeza podem representar aumento de capital, na razão em que constituem fatores da manutenção da boa imagem perante a clientela, esta sim considerada destinatária econômica final.

Com o devido respeito, a insuficiência desse entendimento é patente na medida em que só poderiam ser considerados consumidores as pessoas que consumissem, adquirindo ou utilizando, ao primeiro toque, de forma instantânea, o produto ou o serviço, sem ressalvar que há casos onde o bem ou o serviço, em razão de sua natureza intrínseca, não são assim consumíveis, pois podem protrair seus efeitos econômicos no tempo.

Além disso, só se poderia falar em consumidor, quando este fosse identificado como pessoa não profissional, certo de que em grande parte dos negócios jurídicos travados por um profissional e um fornecedor, é possível se afirmar que não existe uma destinação final econômica, certo de que o elemento lucrativo quase sempre pode ser identificado, de forma real ou virtual, efetiva ou potencial.

\subsection{O Consumidor Bancário}

A questão ora levantada ganha relevo, ao observarmos que na maioria das relações jurídicas travadas entre bancos e pessoas, físicas ou jurídicas, que têm no crédito o objeto de consumo, aquele que contrata com a instituição nunca poderia ser tido como destinatário final econômico, eis que o crédito, ou o dinheiro, intrinsecamente entendido, constitui um objeto que não se consome, pura e simplesmente, realizando, assim, a sua finalística função econômica, pois sempre se pode afirmar que o crédito se transforma em mais crédito, em dinheiro ou em outros bens ${ }^{38}$.

\footnotetext{
38. "Embora o dinheiro, por si mesmo, não seja objeto de consumo, ao funcionar como elemento de troca, a moeda adquire natureza de bem de consumo. As operações de crédito ao consumidor são negócios de consumo por conexão, compreendendo-se nessa classificação todos os meios de pagamento em que ocorre diferimento da prestação monetária, como cartões de crédito, cheques-presente etc." (PASQUALOTTO, A. Conceitos fundamentais no Código de Defesa do Consumidor. São Paulo: RT, 1991, n² 666, p. 50)
} 
Assim, temos conosco que é indispensável uma interpretação mais abrangente do que seja destinatário final, e, portanto, consumidor, sob pena de não aplicarmos o Código de Defesa do Consumidor na relação material onde a vulnerabilidade, fática, econômica ou jurídica (científica), é a mais presente de todas, considerando que não há tecido social onde a relação bancária não esteja inserida ou onde o organismo bancário não imponha sua indiscutivel força econômica.

Nesse ínterim, cabe lembrar que nos termos do art. $2^{a}$, da Lei 8078/90, consumidor não é quem consome, mas simplesmente quem utiliza ou adquire produtos e serviços como destinatário final ${ }^{39}$.

Assim, para que se exista um consumidor, basta à aquisição de um produto (bem móvel ou imóvel, material e imaterial) ou a utilização de um serviço (atividade fornecida ao mercado mediante remuneração) com o objetivo de destinação final, sem a necessidade de qualquer perquirição sobre se existe ou näo uma finalidade lucrativa, ou econômica, no negócio jurídico travado pelo mesmo, mas sim, e unicamente, se existe uma destinação final fática.

Esse entendimento, além de produzir a vantagem prática de deixar para a jurisprudência as condiçōes necessárias para o difícil trabalho de construção da fattispecie, expurgando os casos de abuso, pela possibilidade interpretativa de expressões que possuem certa vagueza de significado, possui a superioridade de não excluir, a priori, pessoas, grupos e entidades, possuidores de incontestável vulnerabilidade, que, de outra forma, jamais poderiam se utilizar do conteúdo protetivo e defensivo da nova legislação.

Em apoio a essa opinião, indispensável trazer o corajoso pensamento de Antonio Carlos Efing, na luta com os teleológicos extremistas "diante dessa conceituação, não resta dúvida de que nos filiamos à corrente maximalista, isto porque somos da opinião que o CDC veio para introduzir nova linha de conduta entre os partícipes da relação jurídica de consumo. Assim, não importa ter vislumbrado a relação de hipossuficiência do consumidor, como querem alguns autores, mas sim uma completa moralização das relaçóes de consumo da sociedade brasileira, onde somente permanecerão nos diversos segmentos da cadeia de consumo aqueles (pessoas físicas ou jurídicas) que assumirem esta posição com todos os seus ônus e encargos, dentre as quais o atingimento da perfeição no fornecimento de produtos e serviços, em total consideração ao consumidor (adquirente ou utente desse produto ou desse serviço) ${ }^{40}$.

\footnotetext{
"3* CAVALIERI FILHO, S. Responsabilidade Civil das Instituiçöes Bancárias por Danos Causados a Correntistas e a Terceiros. São Paulo: RT, 2000, Revista de Direito do Consumidor, na 34, p. 103.

* Contratos e Procedimentos Bancários à Luz do Código de Defesa do Consumudor. Sao Paulo: RT, 2000, p. 4647.
} 
Em combate ao pensamento finalista, ainda comenta o citado autor "o conceito de consumidor pode ser visto sob dois pontos de vista: 'Sob o aspecto econômico, consumidor é considerado todo individuo que se faz destinatário da produção de bens, seja ele ou não adquirente, e seja ou não, a seu turno, também produtor de outros bens. Trata-se, como se observa de uma visão, da noção asséptica e seca que vê no consumidor tão-somente o homo economicus, e como partícipe de uma dada relação de consumo, sem qualquer consideração de ordem política, social, ou mesmo filosófico-ideológica. Do ponto de vista psicológico, considera-se consumidor o sujeito cujas reações se estudam a fim de individualizar os critérios para a produção e as motivações internas que o levam para o consumo. Neste aspecto, pois, perscruta-se as circunstâncias subjetivas que levam determinado indivíduo ou grupo de indivíduos a ter preferéncia por este ou por aquele tipo de produto ou serviço, preocupando-se com tal aspecto certamente a ciência do marketing e da publicidade, assumindo especial interesse quando se trata sobretudo dos devastadores efeitos dessa, se enganosa ou tendenciosa, diante das modernas e sofisticadas técnicas do mencionado marketing e merchandising. Já do ponto de vista sociológico é considerado consumidor qualquer indivíduo que frui ou se utiliza de bens e serviços, mas pertencente a uma determinada categoria social.""41.

No mesmo sentido é o pensamento de Alinne Arquette Leite Novais, que não aceita o entendimento finalista, prelecionando "diante desse posicionamento, a resposta às questóes suscitadas é positiva, no sentido de entender o profissional como consumidor, bastando que adquira $o$ produto ou o serviço como seu destinatário final fático, não importando se de tal fato vai resultar lucro ou não."42.

Sob outro ponto de vista, nos parece acertada a tese maximalista, eis que o próprio Código de Defesa do Consumidor, profetizando a polêmica que poderia surgir em consequêencia de uma interpretação restritiva da conceituação do art. 2a não apta a uma adequação aos objetivos proclamados pela Constituição Federal, estende à sua aplicação, no art. 29 , equiparando a consumidor todas as pessoas, determináveis ou não, que estão expostas a práticas comerciais abusivas ${ }^{43}$.

\footnotetext{
${ }^{41}$ idem, ibidem, p. $47-48$

12. A Teoria Contratual e o Código de Defesa do Consumidor. São Paulo: RT, 2001, p. 128.

4. "Entretanto, essa conceituação fundamental pareceu ao legislador, insuficiente para todos os fins e objetivos dos Capítulos V e VI, eis que nem todas as pessoas, fisicas e juridicas, se encartariam nesse conceito de consumidor (ver comentários aos artigos $2 \mathrm{e} 7$ ), apesar de poderem vir a ser prejudicadas por práticas comerciais, por exemplo)" (ALVM, A. et alh. Código do Consumidor Comentado. Säo Paulo: RT, 1991, p. 10).
} 
Com a formulação desse dispositivo, caem por terra às argumentações finalistas que vinham tentando excluir do âmbito de aplicação do Código de Defesa do Consumidor, não só os profissionais, pessoas fisicas, mas também, e principalmente as pessoas jurídicas, certo de que todas as pessoas, não importando se têm ou não na aquisição ou na utilização de produto ou de serviço uma possível finalidade lucrativa, estão submetidas à abrangência consumerista ${ }^{44}$.

Da mesma forma é o pensamento de Antônio Herman de Vasconcellos e Benjamim, pessoa a quem se deve a justa inclusão, do conceito do art. 29, no Código de Defesa do Consumidor, em conseqüência a um posicionamento contrário ao do lobby empresarial que se formara para retirá-lo por completo, "como no art. $2^{2}$, as pessoas aqui referidas podem ser determináveis ou não. É indiferente estejam essas pessoas identificadas individualmente ou, ao revés, façam parte de uma coletividade indeterminada, composta só de pessoas físicas ou só de pessoas jurídicas, ou até, de pessoas jurídicas e de pessoas físicas. O único requisito é que estejam expostas às práticas comerciais e contratuais abrangidas pelo Código. A redação atual ("expostas às práticas") facilita enormemente o ataque preventivo a tais comportamentos. Uma vez que se prove que, mais cedo ou mais tarde, os consumidores sofreriam a exposição, á está materializada a necessidade de cautela." ${ }^{35}$.

Nesse sentido, Alinne Arquette Leite Novais conclui "assim, qualquer pessoas exposta a uma prática comercial estabelecida pelo Código de Defesa do Consumidor, tais como oferta, publicidade, práticas abusivas, cobrança de dívidas e bancos de dados e cadastros de consumidores, bem como qualquer pessoa que faça um contrato portador de cláusulas abusivas ou que se submete à aceitação de um contrato de adesão, é considerada consumidor e, portanto, está apta a agir como tal, fazendo uso das normas do CDC para defender seus direitos." ${ }^{\text {46 }}$.

A observação da autora é muito importante, principalmente sob o ponto de vista do consumidor bancário, uma vez que grande parte, senão a totalidade, das relações negociais entre clientes e bancos, acontece materializada em

\footnotetext{
* "Se, entretanto, o contrato houver sido realizado buscando-se alcançar uma atividade final, deve-se, a partir dal, perquirir-se da vulnetabilidade do consumidor. Anote-se, entretanto, que raríssimos serão os Litgios envolvendo entidades financeiras, securiturias ou bancárias em que se aplicatá o conceito de consumidor contido neste dispositivo legal (art. $2^{z}$ do CDC), eis que os conflitos advindos dessá espécie de relaçấo juridica certamente apresentax-seão circunscritos à proteção contratual, às práticas comerciais e à publicitade cnganosa, quando então deverá ser aplicado o conceito exarado do art. 29 do CDC)" (DONATO, M. A. Z. Proteção do Consumidor - Conceito e Extensäo. São Paulo. RT, 1993, p. 130-131) 4ódigo de Defesa do Consumidor - Comentado pelos Autores do Anteprojeto. Rio de Janeiro: Forense Universitúria, $1997,5^{\circ}$ ed, p. 210.

* A teoria contratual e o Código de Defesa do Consumidor. São Panlo: RT, 2001, p. 142.
} 
um contrato de adesão ${ }^{47}$, fato que, por si só, já é suficiente para tornar as pessoas, fisicas ou jurídicas, profissionais ou não, com a qualidade de consumidoras.

Inobstante isso, mais contribui para uma derrocada da interpretação finalista, o art. 17, do Código de Defesa do Consumidor, ao equiparar a consumidor todas as pessoas que forem vítimas de produto ou de serviço que causem dano ${ }^{48}$. No mesmo sentido, éo próprio parágrafo único, art. $2^{\text {a }}$, que equipara a consumidores a coletividade de pessoas que tenha intervindo nas relaçôes de consumo.

Realizada essa pequena mas sólida exposição, em que entendemos que consumidor bancário pode ser entendido, em uma visão maximalista do Código de Defesa do Consumidor, como qualquer pessoa, física ou jurídica, profissional ou não, que trave relações com uma pessoa jurídica que forneça produtos ou serviços bancários, mediante remuneração, passemos à análise do fornecedor de produtos ou serviços.

\subsection{A Extensão do Conceito de Fornecedor}

Para o outro pólo da relação de consumo, o Código de Defesa do Consumidor, no art. $3^{\mathfrak{a}}$, elegeu o fornecedor, definindo-o, com a maior abrangência possível, como sendo toda a pessoa física ou jurídica, pública ou privada, nacional ou estrangeira, bem como os entes despersonalizados, que desenvolvam atividades de produção, montagem, criação, construção, transformação, importação, exportação, distribuição ou comercialização de produtos ou prestação de serviços.

De maneira sintética, como nos informa Arruda Alvim, podemos dizer que "...fornecedor é todo ente que provisione o mercado de consumo de produtos ou de serviços." ${ }^{49}$.

f: "O contrato de adesão é ofercido ao público em um molelo uniforme, geralmente impresso, faltando apenas preencher os dados referentes à identificaçĩo do consumidor-contratante, do objeto e do preço. Assin, aqueles que, como consumidores, desefarem contratar com a empresa para adquirirem bens ou serviços fá receberão pronta e regulamentada a relaça contratual, não poderão eferivamente discutir, nem negociar singularmente os termos e condiçoes mais impotantes do contrato. Desta maneira, limita-se o consumidor a aceitar em bloco (muitas vecs sem sequer ler completamente) as dátulas, que foram unilateral e uniformementc préclabotadas pela empresa, assunindo, assim, um pape de simples aderente à vontade manifestada pela empresa no instrumento contratual massificado." (MARQUES, C. M. Contratos no Código de Defesa do Consumidor. Săo Paulo: RT, 1995, $2^{\circ}$ ed., vol. 1. p. 44).

*" "Conforme visto nos comentários a artigo 2", em algumas sitalaçöes, o conceito geral de consumidor poderia ser insuffciente para abranger todas as relaçoes de consumo que requerem amparo legal. Isto é o que ocorre nesta Seção II, referente ao fato do produto ou do serviç, e tem o presente artigo a virtude de preencher, completar o aspecto de abrangèncta do conceito de consumidor, estendendo a proteçăo deste Código a uma gama maior de situações onde possa ocorrer dano." (ALVM, A et alii. Código do Consumidor Comentado. São Paulo: RT, 1991, p. 49).

1"idem. ibidem, p. 17. 
Do referido dispositivo, pode ser fornecedor toda a pessoa física, desde que maior e capaz, nos termos do Código Civil, arts. $5^{a}$ a $9^{a}$, bem como todas as pessoas jurídicas, privadas ou públicas, nacionais e estrangeiras, inclusive os entes despersonalizados ${ }^{50}$, desde que desenvolvam atividades ${ }^{51}$ de produção, montagem etc.

Nesse passo, cabe ressaltar que a enumeração das atividades realizadas pelo fornecedor, constantes no art. $3^{a}$, caput, não é taxativa, mas meramente exemplificativa, fato constatável não só à luz da Constituição Federal, que propóe uma tutela exauriente dos interesses e direitos do consumidor, mas também porque é impossível uma previsão atual de quantas e de quais serão as futuras atividades que poderão ser exercidas pelo fornecedor, em virtude dos progressos da ciência na transmodernidade.

Para apoiar a tese, Arruda Alvim menciona "percebe-se que a enumeração das atividades que caracterizam o fornecedor poderia parecer pretender ser exauriente. Todavia, dadas às características especiais desta lei de proteção ao consumidor, não nos parecem que devam ser entendidas como taxativas, mas sim como exemplificativas (numerus apertus) das atividades que normalmente envolvem as relações de consumo e que possam gerar ao consumidor direitos exercitáveis por meio deste Código outra atividade de natureza similar, semelhante ou de natureza equivalente às atividades enumeradas.". ${ }^{2}$

\footnotetext{
50 "Tem-se por conseguinte que fornecedor $\hat{e}$ qualquer pessoa fisica, ou seja, qualquer um que, a titulo singular, mediante desempenho de atividade mercantil ou civil e de forma habitual ofereça no mercado produtos ou serviços, a juridica, da mesma forma, mas en associação mercantil ou civil de forma habitual. ... fornecedor pode ser público ou privado, entendendo-se no primeiro caso o próprio Poder Público, por sí ou entäo por stas empresas públicas que desenvolven atividade de produço, ou anda as concessionárias de serviços públicos, sobrelevando-se salientar nesse aspecto que un dos direitos doS consumidores expressamente consagrado pelo art. $6^{2}$, mais precisamente no seu inciso $X$, é a adequada $e$ eficaz proteçäo dos serviços públicos en geral. A referencia aos entes desprovidos de personalidade juridica no conceito de fornecedor aplicase, rigorosamente falando, somente ao espolio e ao nascituro. ... condomínio horizontal e a massa falida, com efeito, näo podem exercer atividade cconómica e assim, näo são suscetivess de enquadramento no conceito de consumidor. ... Na hipotese do empresátrio ter a sua falência decretada apos o fornecimento objeto do litígio, o consumidor irá demandar a massa falida. No entanto, isso não quer dizer que esta tenha se tomado fornecedota. Ela apenas é a substituta processual do fornecedor, en razão da norma especifica da legislaçio falimentax." (COELHO, F. U. O Empresário e os Direitos do Consumidor. São Paulo: Sarava, 1994, p. 100-101).

51 "A expressão "atividades" no caput do art $3^{2}$, parece indicar a exigencia de alguma reiteraço ou habitualidade, mas fica clara a intençõo do legislador de assegurar a inclusão de um grande número de prestadores de gerviços no campo de aplicaço do $\mathrm{CDC}$, à dependência única de ser o cocontratante um consumidor." (MARQUES, C. M. Contratos no Código de Defesa do Consumidor. São Paulo: RT, 1995, $2^{\circ}$ ed, wol. 1, p. 116).

Codigo do Consumidor Comentado. São Paulo: RT, 1991 , p. 17.
} 


\subsection{O Fornecedor Bancário}

Deveras importante para a completa compreensão do que seja fornecedor, principalmente no tocante ao fornecedor bancário, é a definição de produto e de serviço, obtidas pelos $\$ 1^{\underline{a}}$ e $\$ 2^{2}$, art. $3^{\underline{a}}$, do Código de Defesa do Consumidor, respectivamente.

Para caracterizar o produto, o Código de Defesa do Consumidor, $\$ 1 \stackrel{\text { a }}{\text {, }}$ art. $3^{\text {a }}$, dispõe que pode ser qualquer bem, móvel ou imóvel, material e imaterial.

Como afirma Antonio Carlos Efing, citando José Geraldo Brito Filomeno, o conceito de objeto da relação como 'produto' não é o mais adequado para o caso, melhor teria sido se o legislador tivesse utilizado a expressão 'bens e não produtos, porquanto o primeiro termo retro-referido é muito mais abrangente e, aliás, mais técnico, tanto do ponto de vista jurídico como do ponto de vista da economia política. E tal aspecto fica ainda mais flagrante quando se tem em conta que no caso se há que tratar de bens como efetivos objetos das relações de consumo, ou seja, como aquilo que está entre (do latim inter + essere) os dois sujeitos da relação de consumo." ${ }^{3} 3$

Inobstante isso, é indispensável notar o sentido de abrangência que o Código de Defesa do Consumidor quer chegar para denominar o objeto da relação consumerista, certo que bens móveis e imóveis, materiais e imateriais constituem uma classificação de significado extenso, devendo constituir a viga mestra de qualquer outra classificação que se pretenda mais específica.

Em resumo, para os efeitos do Código de Defesa do Consumidor, art. $3^{\mathrm{a}}, \S 1^{\mathrm{a}}$, qualquer bem pode ser classificado como "produto", desde que corresponda ao objeto da relação de consumo ${ }^{54}$.

Nesse passo, quanto ao tema que nos afeta, como ressaltou Antonio Carlos Efing, a jurisprudência já se manifestou nos seguintes termos, "O CDC rege as operações bancárias, inclusive de mútuo ou de abertura de crédito, pois relações de consumo. O produto da empresa de banco é o dinheiro ou o crédito, bem justificadamente consumível, sendo, portanto, fornecedora; e consumidor o mutuário ou creditado." 55 .

\footnotetext{
ST Contratos e procedimentos Bancários à luz do Código de Defesa do Consumidor. São Paulo: RT, 2000, p. 65.

${ }^{\text {it }}$ ALVIM. A. et alir. Código do Consumidor Comentado. São Paulo: RT, 1991, p. 18.

${ }_{55}$ Contratos e procedimentos Bancários à luz do Código de Defesa do Consumidor. São Paulo: RT, 2000, p. 67-68.
} 
Sobre o posicionamento da jurisprudência também se refere Vilson Rodrigues Alves, quando afirma "como superiormente se afirmou na jurisprudência, o Código de Proteção do Consumidor adotou conceito amplo acerca de produto, explicitando como qualquer bem, móvel ou imóvel, material ou imaterial. Por isso mesmo, os rendimentos de um investimento financeiro - como a poupança e outros - constituem esse produto referido na lei, utilidade do consumidor. ${ }^{\$ 5}$.

Efetivamente, mesmo que o dinheiro ou o crédito, intrinsecamente considerados, não possam ser chamados de objetos ${ }^{57}$, podem ser considerados bens, em quaisquer das acepções da palavra, o que é mais do que suficiente para denominá-los produtos, nos termos explicitados pelo $\$ 1^{\underline{a}}$, art. $3^{\underline{a}}$, do Código de Defesa do Consumidor.

Desta forma, também através da conceituaçã̃o de dinheiro ou de crédito como produtos, pois são bens, pode ser caracterizada a relação de consumo entre os bancos fornecedores e a sua clientela de consumidores.

Mais importante para o que ora se propõe, é a conceituação de serviço, disposta no $\S 2^{2}$, art. $3^{a}$, do Código do Consumidor, que afirma ser serviço qualquer atividade fornecida ao mercado de consumo, mediante remuneração, inclusive as de natureza bancária, financeira, de crédito e securitária, salvo as decorrentes de relação trabalhista.

Embora sobre o tema não exista tanta polèmica na doutrina quanto em relação à expressão 'consumidor', há uma clara resistência dos bancos, e demais operadoras de crédito, na sua inclusão como fornecedoras de serviços, através da dinâmica legislativa referenciada pelo Código de Defesa do Consumidor.

Essa resistência resta mais caracterizada, ao observarmos que o próprio Banco Central do Brasil, através do Conselho Monetário Nacional, no dia 26.06.2001, editou a Resolução $n^{\underline{a}} 2878$, que dispóe sobre procedimentos a serem observados pelas instituições financeiras na contratação de operações e na prestação de serviços ao público em geral.

É interessante notar que a mencionada Resolução, que mais parece uma espécie de codex administrativo, é parafraseada e espelhada no Código de Defesa do Consumidor, uma vez que ressalta, sem nunca mencionar a palarra 'consumidor', diversos princípios e dispositivos daquele, tais

\footnotetext{
Responsabilidade Civil dos Estabelecimentos Bancários. Campinas: Bookseller, 1996, p. 94. PASQUALOTTO A. Conceitos fundamentais no Código de Defesa do Consumidor. Săo Paulo: $\mathrm{RT}, 1991, \mathrm{n}^{2} 666$, p. 50.
} 
como, apenas título de exemplo, no inc. I, art. 1ª que deverá ser observada a "transparência nas relações contratuais preservando os clientes e o público usuário de práticas não eqüitativas, mediante prévio e integral conhecimento das cláusulas contratuais, evidenciando, inclusive os dispositivos que imputem responsabilidades e penalidades." 58 .

Em nosso modesto entendimento, a intervenção do Banco Central do Brasil nessa matéria possui, no minimo, dois significados: a) que os bancos e instituições financeiras não admitem o seu enquadramento como fornecedoras; b) que os bancos e instituições financeiras cometem, continuamente, ilícitos pré-contratuais, contratuais e extracontratuais.

Com opinião a favor da não caracterização dos bancos como fornecedores de serviços, está Arnoldo Wald, que enuncia

"4.1 A nova lei não se aplica às operaçôes de produção, poupança e investimentos, ou seja, no campo específico em que se colocou o parecer, à captação de recursos pelas instituições financeiras, sob qualquer forma. 4.2 A nova lei também não se aplica às operações de empréstimos e outras análogas pelos bancos, pois o dinheiro e o crédito constituem produtos adquiridos ou usados pelo destinatário final, sendo, ao contrário, instrumentos ou meios de pagamento, que circulam na sociedade e em relação aos quais não há destinatário final (a não ser os colecionadores de moeda e o Banco Central quando retira a moeda de circulação)."

Em relação ao tema, mesmo os autores que partilham uma visão finalística mais moderada do conceito de consumidor são unânimes em afirmar, ante a clareza do $\S 2^{a}$, art. 3 , que os bancos e instituições financeiras estão incluído na categoria de fornecedores. Nesse sentido, mister revelar - pensamento de Cláudia Lima Marques "podemos denominar, genericamente, contratos bancários aqueles concluídos com um banco ou uma instituição financeira. Entre eles destacam-se o depósito bancário, depósito em conta corrente, conta poupança, ou a prazo fixo, o contrato de custódia e guarda de valores, o contrato de abertura de crédito, de empréstimo e o de financiamento. Na sociedade atual os contratos bancários popularizam-se, não havendo classe social que não se dirija aos

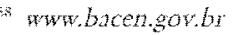

39 Direito do Consumidor e suas repercussöes em relaçăo às Instituiçöes Financeitas. São Paulo: RT, 1991, Revista dos Trbunais $\mathrm{n}^{2} 666, \mathrm{p} .16$

"No mesmo sentido: Do Regime Legal da Responsabilidade das Instituições Financeiras pelo Extravio de Titulos de Crédito que lhes Foram Entregues Para Cobrança Através de Endosso-Mandato. São Paulo: RT, 1995, Revista dos Tribunais n $\mathrm{n}^{\mathrm{3}} 718$, p. 63-78; Teoria da Imprevisão e as Peculiaridades do Direito Banćrio. Săo Paulo: RT, 1998, Revista de Direto Bancario e do Mercado de Capitais nª 2, p. 47.62.
} 
bancos para levantar capital, para recolher suas economias, para depositar seus valores ou simplesmente pagar suas contas. É o contrato de adesão por excelência, é uma das relações consumidor-fornecedor que mais se utiliza do método de contratação por adesão e com 'condições gerais' impostas e desconhecidas. A caracterização do banco ou instituição financeira como fornecedor está positivada no art. $3^{\frac{a}{a}}$, caput do CDC e especialmente no $\$ 2^{a}$ do referido artigo, o qual menciona expressamente como serviços as atividades de 'natureza bancária, financeira, de crédito,",6!.

Não obstante, para que possamos excluir a tese da não caracterização dos bancos como fornecedores, deveremos analisar os dois principais elementos dispostos no conceito, ou seja, a existência de um serviço e de uma remuneração respectiva.

Com salienta James Marins "inicialmente, cremos que se deva entender a expressão 'mediante remuneração' não apenas como representativa da remuneração direta, isto é o pagamento diretamente efetuado pelo consumidor ao fornecedor. Compreende também a remuneração do fornecedor o benefício comercial indireto advindo de prestações de serviços aparentemente gratuitos, assim como a remuneração 'embutida' em outros custos." ${ }^{\prime 2}$.

Assim, nesse aspecto, não restam dúvidas de que o banco, as instituições financeiras e de crédito são fornecedoras, nos estritos termos do Código de Defesa do Consumidor, sendo impossível encontrar algum serviço por elas oferecido que não seja realizado mediante uma remuneração, mesmo que o lucro advenha de forma indireta, ou até mesmo benemérita ${ }^{63}$.

Apenas para reforçar, vale trazer o conceito que Nelson Abrão defere para bancos, com o objetivo de se extrair que a atividade é exercida em busca de remuneração "na terminologia do moderno Direito Comercial, os bancos são empresa (organização harmônica de capital e trabalho para o exercício de uma atividade econômica de produção ou de troca de

51 Contratos no Código de Defesa do Consumidor. São Paulo: RT, $2^{2}$ ed., vol. 1, p. 44.

22 Responsabilidade da empresa pelo fato do produto. São Panlo: RT, 1993, p. 82.

4.3. "Todavia, a gratuidade näo é faror que, por si só, sirva à negativa da existència da relaçào de consumo. As amostras grátís săo práticas comerciais (cap. V do tit $\mathrm{l}$ ) e podem ser consideradas abusivas se remetidas ou entregues ao consumidor sem solicitaçäo prévia (PAQUOLLATO, A. Conceitos Fundamentais do Código de Defesa do Consumidor. São Patlo: RT, 1991, Revista dos Tribunais n ${ }^{2} 666$, p. 53).

Em sentido contrário, com reservas, à adição do serviço gratuito é o pensamento de Josć Cretella Júnior Comentários ao Código do Consumidor. Rio de Janeiro: Forense, 1992, p. 15. 
bens e serviços), e não mero estabelecimento (complexo de bens, materiais e morais de que dispóe o empresário para o exercício de sua atividade). ...podemos, com base na análise da atividade que constitui seu objeto, definir banco como sendo a empresa que, com fundos próprios, ou de terceiros, faz da negociação do crédito a sua atividade principal (cf. n. 2 retro)" 64 .

Da definição trazida pelo autor, facilmente podemos concluir que a os atos realizados pela instituição bancária, possuindo como atividades principais à intermediação e à mobilização de créditos, visando o lucro, o aumento de capital, são remuneradas, o que mais contribui para incluir os bancos no rol dos fornecedores típicos.

Até mesmo a classificação de negócios bancários, mais financeira que jurídica, nos dá a plena noção de que a atividade exercida pelos bancos no mercado de consumo, mediante uma remuneração, nos permite classifica-los como fornecedores, como nos informa Aramy Dornelles da Luz "os negócios bancários, em linguagem tecno-contábil, são chamados operações. Negociar com uma instituição financeira é referido como operar. Do ponto de vista jurídico-contábil a palavra operação passou a denominar o aspecto formal e material da execução de um negócio, isto é, sua parte procedimental. Constitui uma operação bancária todo e qualquer negócio que se realize entre um Banco e seu cliente e que atenda ao fim comercial do banqueiro." 65 .

Sendo assim, duvidas não persistem de que as atividades desempenhadas pelos bancos, instituiçôes financeiras e de crédito, quer na prestação de serviços ou utilidades a seus clientes, quer na concessão de mútuos ou financiamentos, as transforma em fornecedoras de serviços, para todos os termos da lei.

Com o indispensável respeito, apenas a título de reflexão, é preciso dizer que a interpretação da norma não poderia ser diferente, certo de que inundada pela perspectiva constitucional, não excluiria de sua abrangência uma das figuras que mais podem contribuir, em razão de sua incontestável força, para a realização mais completa da pessoa, no sentido de constituir um elemento que possa contribuir, em substância, para que todos possuam uma existência digna e condigna, conforme determina a justiça social.

\footnotetext{
Direito Bancário. São Paulo: $1 \mathrm{~d}, 1998,4^{\circ}$ ed, p. 3738.

${ }^{\circ}$ Negócios Jurídicos Bancários. São Paulo: Juarez de Oliveira, $2^{\circ}$ ed., p. 21.
} 
Não se quer dizer aqui, que os bancos devem deixar de perseguir o lucro, o aumento de capitais, ou seja, seus objetivos mais preponderantes, mas tão somente que a sua atividade deve ser exercida com responsabilidade, responsabilidade constitucional, na exata medida em que, sem perder de vista seus fins, possa conviver e trabalhar para a criação de uma sociedade igualitária, onde não hajam excluídos e marginalizados.

Realizada essa breve exposição, onde pudemos observar que o banco, as instituições financeiras e as de crédito, podem ser entendidas como fornecedoras, nos é necessário formular uma conclusão, que sem a pretensão de estabelecer conceitos rígidos, propõe uma interpretação moralizante, ética e social do conteúdo das normas trazidas pelo Código de Defesa do Consumidor, en função dos objetivos libertários e igualitários, de realização da pessoa, traçados pela Constituição Federal.

\section{Conclusão}

Após o estudo apresentado, nos é clara a indispensabilidade de uma interpretação extensiva dos conceitos sobre os protagonistas da relação de consumo, em busca de uma efetiva justiça social, ressaltando o respeito e a consideração aos objetivos, princípios e fundamentos da Constituição Federal, presentes no Código de Defesa do Consumidor, fato que nos obriga a concluir o seguinte:

A) para que exista um consumidor bancário, basta à aquisição de um produto (bem móvel ou imóvel, material e imaterial) ou a utilização de um serviço (atividade fornecida ao mercado mediante remuneração) com o objetivo de destinação final, sem a necessidade de qualquer perquirição sobre se existe ou não uma finalidade lucrativa no negócio jurídico, mas sim se existe uma destinação final fática;

B) o consumidor bancário pode ser entendido como qualquer pessoa, física ou jurídica, profissional ou não, que trave relações com uma pessoa jurídica que forneça produtos ou serviços bancários, financeiros ou de crédito, mediante remuneração;

C) apesar do dinheiro e do crédito não poderem ser denominados objetos, intrinsecamente, podem ser considerados bens, em quaisquer das acepçốes da palavra, o que é mais do que suficiente para denominá-los produtos;

D) os bancos, as instituições financeiras e as de crédito, são fornecedoras 
de serviços, nos termos do Código de Defesa do Consumidor, sendo impossivel encontrar alguma atividade por elas realizada que não seja cumprida mediante uma remuneração, mesmo que o lucro advenha de forma indireta ou gratuita.

\section{BIBLIOGRAFIA}

ABRÃO . N. Direito Bancário. São Paulo: RT, $1998,4^{\circ} \mathrm{ed}$.

ALVES, W. R. Responsabilidade Civil dos Estabelecimentos Bancários. Campinas: Bookseller, 1996, p. 94.

ALVIM, A. et alli. Código do Consumidor Comentado. São Paulo: RT, 1991.

ARRUDA, J.J. de. História Antiga e Medieval. São Paulo: Ática, 1989, $11^{\circ}$ ed. BARROS, S. T. O Princípio da Proporcionalidade e o Controle de Constitucionalidade das Leis Restritivas de Direitos Fundamentais. Brasília: Brasília Jurídica, 1996.

BENJAMIN, A. H. B. O Conceito Jurídico de Consumidor. São Paulo: RT, $1988, \mathrm{n}^{\mathrm{a}} 628$

CAVALIERI FILHO, S. Responsabilidade Civil das Instituiçōes Bancárias por Danos Causados a Correntistas e a Terceiros. São Paulo: RT, 2000, Revista de Direito do Consumidor $\mathrm{n}^{\mathrm{a}} 34$.

CENEVIVA, W. Publicidade e Direito do Consumidor. São Paulo: RT, 1991. COELHO, F. U. O Empresário e os Direitos do Consumidor. São Paulo: Saraiva, 1994.

COELHO, L. F. Saudade do Futuro. Florianópolis: Boiteux, 2001. COMPARATO, F. K. A Proteção do Consumidor na Constituição brasileira. São Paulo: Revista de Direito Mercantil, v. 80.

COSTA, J. M. O Direito Privado como um "sistema em construção", Revista de Informação Legislativa, $\mathrm{n}^{2}$ 139, Brasília, 1998.

CRETELLA JÚNIOR, J. Comentários ao Código do Consumidor. Rio de Janeiro: Forense, 1992.

DONATO, M. A. Z. Proteção do Consumidor - Conceito e extensão. São Paulo: RT, 1993.

EFING, A. C. Contratos e Procedimentos Bancários à Luz do Código de Defesa do Consumidor. São Paulo: RT, 2000.

FERREIRA FILHO, M. G. Curso de Direito Constitucional. São Paulo: Saraiva, $1990,18^{\circ} \mathrm{ed}$. 
FILOMENO, J. G. B. et alii. Código de Defesa do Consumidor Comentado pelos Autores do Anteprojeto. Rio de Janeiro: Forense Universitária, $1997,5^{\circ} \mathrm{ed}$.

GIORGIANNI, M. O Direito Privado e suas Atuais Fronteiras. Porto Alegre: RT, 1998, v. 787.

GOMES, O. A Agonia do Código Civil. Rio de Janeiro: Revista de Direito Comparado Luso-Brasileiro, Forense, 1988, v. 757.

KARAM, M. O Processo de Codificação do Direito Civil Inovações da Parte Geral e do Livro das Obrigações. São Paulo: Revista dos Tribunais, 1998, v. 757.

LOWENSTEIN, K. Teoria de la Constitución. Barcelona: Ariel, 1970, $2^{\circ}$ ed. LUZ, A. D. da. Negócios Jurídicos Bancários. São Paulo: Juarez de Oliveira, $2^{\circ} \mathrm{ed}$.

MARINS, J. Responsabilidade da Empresa pelo Fato do Produto. São Paulo: RT, 1993.

MARQUES, C. M. Contratos no Código de Defesa do Consumidor. São Paulo: RT, $1995,2^{\circ}$ ed., vol. 1.

NOVAIS. A. A. L. A Teoria Contratual e o Código de Defesa do Consumidor. São Paulo: RT, 2001.

PASQUALOTTO, A. Conceitos Fundamentais no Código de Defesa do Consumidor. São Paulo: RT, 1991, nª 666.

PEDRO, A. História Moderna e Contemporânea. São Paulo: FTD, 1991. TEPEDINO, M. C. A Caminho de um Direito Civil Constitucional. São Paulo: Revista de Direito Civil, Imobiliário, Agrário e Empresarial, $1993, \mathrm{n}^{\mathrm{a}} 65$.

TIMM, L. B. A Prestação de Serviços Bancários Via Internet (home banking) e a Proteção do Consumidor. São Paulo: RT, 2001, Revista do Consumidor $n^{\underline{z}} 38$.

WALD, A. Direito do Consumidor e suas Repercussões em Relação às Instituiçöes Financeiras. São Paulo; RT, 1991, Revista dos Tribunais $n^{\underline{a}} 666$. Do Regime Legal da Responsabilidade das Instituições Financeiras Pelo Extravio de Títulos de Crédito que Thes Foram Entregues para Cobrança Através de Endosso-Mandato. São Paulo: RT, 1995, Revista dos Tribunais $\mathrm{n}^{\mathrm{a}} 718$.

Teoria da Imprevisão e as Peculiaridades do Direito Bancário. São Paulo: RT, 1998, Revista de Direito Bancário e do Mercado de Capitais $n^{\mathrm{a}} 2$. 